\title{
NEW METHOD FOR EXPERIMENTAL MODELING OF PANCREAS TRAUMAS FOR WISTAR RATS AND CYTOKINE LEVEL CHANGES IN THESE MODELS
}

\author{
Edgars Zarembo, Olga Mežale, Aleksandrs Mikitins, Leontine Antonovica, Jekaterina Petla, \\ Aigars Petersons, Riga Stradins University, aigars.petersons@ @rsu.lv, zarembo@ apollo.lv
}

The incidence of pancreas traumas (PT) is low; however, lethality in case of PT remains unchangingly high. The aim of the present study is to develop a technically simple, easily repeatable method for experimental modelling of PT of various degrees of severity for Wistar rats and study changes in plasma levels of cytokines (IL-1 $\beta$; IL-6; TNF $\alpha$; IL-10; MCP-1; IL-12(p70)) for experimental models. Under general anaesthesia 50 animals were performed laparotomy and were made damages of pancreas tissues of various severity standardized using Crile clamps. $24 \mathrm{~h}$ and $72 \mathrm{~h}$ after creating PT the samples of blood serum were taken. In autopsy all animals were identified the features of pancreatitis. Severity of pancreatic histologic injury was associated with the impact severity. Plasma MCP-1 levels were significantly $(\mathrm{p}<0,05)$ increased in $24 \mathrm{~h}$ and $72 \mathrm{~h}$ samples. The method with putting Crile clamps under general anaesthesia shall be applied for creation of PT for Wistar rats and let model various degrees of PT severity. MCP-1 might play a pivotal role in inflammatory response of acute pancreatitis.

UDC Number: 616-001, DOI: 10.12955/cbup.2013.41

Keywords: pancreas, trauma, pancreatitis, model, cytokines

\section{Introduction}

The incidence of pancreas traumas is low (0.4/ 100000$)$, they comprise only 1-3\% of the abdominal traumas; however, lethality in case of PT remains unchangingly high (12-73\%) (El-Boghdadly, AlYousef, \& Al Bedah, 2000). Traumas are wide spread (15-40\%) in the etiology of children's acute pancreatitis (Kandula \& Lowe, 2008; Park et al., 2009). Up to $10 \%$ of children, who have a blunt abdominal cavity trauma, have pancreatic injuries, and the frequency of these cases tends to increase (Matsuno, Huang, Garcia, Roy \& Davis 2009). In comparison with adults, children more frequently get an isolated pancreatic trauma, which probably indirectly indicates greater vulnerability of pancreatic tissues. The vulnerability of child's pancreas is common due to softer tissues and weaker anatomic protection by the anterior abdominal wall and other organs (Ruszinko, Willner \& Olah, 2005). In case of PT among children the opportunities to accumulate clinical experience are very limited. These conditions determine the necessity for new researches and do not let avoid the use of laboratory animals' models. The existing experimental models of PT are technically complex, not always easily repeatable; the opportunities to model the degree of pancreas damage are very limited. Rau et al. (2005): "A large body of clinical and experimental evidence suggests that cytokines are key factors in the pathomechanism of local and systemic complications of acute pancreatitis." 
Determination of cytokines' level in acute phase of illness may be important for early prediction of disease severity.

The aim of the paper was to develop a technically simple, easily repeatable method for experimental modelling of PT of various degrees of severity for Wistar rats and study changes in plasma levels of cytokines (IL-1 $\beta$; IL-6; TNF $\alpha$; IL-10; MCP-1; IL-12(p70)) for vairous degrees of experimental PTRP models for Wistar rats.

\section{Pancreas traumas experiment}

Under general anaesthesia 50 experimental animals - Wistar male rats (220-250 g) were performed upper middle laparotomy $(2 \mathrm{~cm})$ and applying transillumination of pancreas tissues and $10 \mathrm{x}$ optical magnification there were made damages of pancreas tissues of various severity standardized using Crile clamps (Aesculap BH 167 R). Male rats were chosen to avoid the possibility of estrogen cycle influence on the pathological process. Animal experiments were performed according to the Regulations Nr.1131 of the Cabinet of Ministers of the Republic of Latvia, Regulations for the experimental animal breeders, suppliers and users registration, the order that the actions with the experimental animals are done, and provided welfare for experimental animals" and taking into account European Parliament and Council 22nd September, 2010, Directive 2010/63/ES about protection of the animal used in scientific purposes. The research was done by Food and Veterinary service and Latvian Animal Protection Ethics Council authorization. All animals received standard rat chow and tap water ad libitum and were maintained on a 12-h light/dark cycle at ambient temperature and $60 \%$ relative humidity. 12 hours before the experiments the animals were not fed, access to water was not limited. This was done in order to standardize the study conditions, causing the pancreatic secretory cell cycle synchronization. All surgical procedures were performed on a heated operating table under general anesthesia using a combination of ketamin and dexdomitorum with sterile instruments under aseptic conditions. Group $1-10$ rats had their pancreas tissues squeezed for $10 \mathrm{sec}$ without tissue rapture, Group $2-10$ rats had their tissues squeezed for $10 \mathrm{sec}$. between 2 Crile clamps damaging tissues without damaging the pancreas duct, in Group 3 - 13 rats had their tissues squeezed for $10 \mathrm{sec}$. damaging tissues with damaging the pancreas duct, in Group $4-17$ rats had their tissues squeezed for 10-20 sec. between 2 Crile clamps making full cross-damage of pancreas. The abdominal cavity was closed using 4/0 Vicryl sutures. The surgery took about $10 \mathrm{~min}$ to perform. The animals were returned to individual cages and had free access to water. The cages were placed under a heating lamp to help maintain body temperature in the immediate postoperative period. $2,5 \mathrm{ml}$ of $0,9 \%$ saline solution was injected subcutaneously to compensate for fluid loss after the operation. $24 \mathrm{~h}$ and $72 \mathrm{~h}$ after creating PT the samples of blood serum were taken from the survived animals to examine cytokines IL-1 $\beta$; IL-6; TNF $\alpha$; IL-10; MCP-1; IL-12(p70). After $24 \mathrm{~h}$, blood was obtained from the vena caudalis. The animals were sacrificed by exsanguination after $72 \mathrm{~h}$. The specimens of blood were centrifuged with $3000 \mathrm{rpm}$ for 10 minutes and the supernatant was collected and then frozen at $-70 \circ \mathrm{C}$. Autopsy was performed to all animals taking tissues for histological examination (pancreas, lung, kidney, liver, spleen). All preparations were fixed in $10 \%$ formaldehyde, dehydrated with the gradient alcohol, and embedded lung tissue was cut into - $5 \mu \mathrm{m}$ slides, stained by hematoxylin-eosin, and examined under the light microscope. Specimens were graded by pathologist blinded to the experimental setup using a scoring system for the extent and severity of pancreatitis $(0-4$, normal to severe, respectively), the degree of interstitial edema, hemorrhage, hyperemia, necrosis, leukocyte infiltration of the pancreatic tissue of interstitial edema, hemorrhage, hyperaemia, necrosis, leukocyte infiltration of the pancreatic tissue as previously described (Weber et al., 2000; Rakonczay et al., 
2002). Statistical differences were analyzed using the Mann -Whitney U test for the comparison among different groups and the Wilcoxon test for the comparisons within each group at different times. A $P$ value $<0.05$ indicated statistical significance.

\section{Results}

Up to $72 \mathrm{~h}$ in Group 1 no animals died, in Group 2 one animal died, in Group 3 four animals died, in Group 4 eight animals died. In autopsy all animals were identified the features of pancreatitis - edema, haemorrhages, hemorrhagic exudation. Animals having a damage of the pancreas duct or crossdamage of pancreas often have extensive steatonecroses, pancreonecroses. Severity of pancreatic histologic injury was associated with the impact severity. All groups showed an increase of cytokines IL-1 $\beta$; IL-6; IL-10; IL-12(p70) compared to the control, but did not reach a statistically significant level. Plasma MCP-1 levels were significantly increased $(\mathrm{p}<0,05)$ in $24 \mathrm{~h}$ and $72 \mathrm{~h}$ samples.

\section{Conclusion}

We demonstrate that PT modeling method for Wistar rats with standardized putting Crile clamps on pancreas during laparotomy under general anesthesia is technically simple, easily repeatable method. It allows accurately imitate various degrees of PT severity. Using of this method in experimental medicine could facilitate the research of pancreas injuries and posttraumatic pancreatitis. We conclude that more than 24 hours after the injury MCP-1 might play a pivotal role in inflammatory response of acute pancreatitis.

\section{References}

Kandula L. \& Lowe, M.E. (2008). Etiology and outcome of acute pancreatitis in infants and toddlers. J. Pediatr., 152, 106 - 110. Retrieved January, 20, 2013, from http://www.ncbi.nlm.nih.gov/pubmed/18154910, doi: 10.1016/j.jpeds.2007.05.050, PMid:18154910

Matsuno, W.C., Huang, C. J., Garcia, N. M., Roy, L. C. \& Davis, J. (2009). Amylase and lipase measurements in paediatric patients with traumatic pancreatic injuries. Injury, 40 (1), 66 - 71. Retrieved January, 30, 2013, from http://www.sciencedirect.com/science/journal/00201383/40/1 doi: 10.1016/j.injury.2008.10.003, PMid:19135195

Park, A., Latif, S. U., Shah, A. U., Tian, J., Werlin, S., Hsiao, A., et al. (2009). Changing referral trends of acute pancreatitis in children: a 12-year single-center analysis. J. Pediatr. Gastroeterol. Nutr., 49, 316 - 322. http://dx.doi.org/10.1097/MPG.0b013e31818d7db3 PMid:19503003 PMCid:3034387

Rakonczay, Z. Jr., Takacs, T., Ivanyi, D., Mandi, Y., Papai, G., Boros, I. et al. (2002). The effects of hypo-and hyperthermic pretreatment on sodium taurocholate-induced acute pancreatitis in rats. Pancreas, 24, 83-89. http://dx.doi.org/10.1097/00006676-200201000-00011 PMid:11741186

Rau, B.M., Krüger, C.M., Schilling, M.K. (2005). Anti-cytokine strategies in acute pancreatitis: pathophysiological insights and clinical implications. Annales Academiae Medicae Bialostocensis. (50), pp. 106-115. 
Ruszinko, V., Willner, P. \& Olah, A. (2005). Pancreatic injury from blunt abdominal trauma in childhood. Acta Chir. Belg., 105, p. 6. PMID: 16018521

Sami El-Boghdadly, Zyad Al-Yousef \& Khalid Al Bedah (2000). Pancreatic injury: an audit and a practical approach. Ann. R.Coll.Surg.Engl., 82, 258 - 262. Retrieved January, 30, 2013, from http://pubmedcentralcanada.ca/pmcc/articles/PMC2503512/pdf/annrcse01626-0044.pdf

Weber, H., Wagner, A. C., Jonas, L., Merkord, J., Hofken, T., Nizze, H., Leitzmann, P., Goke, B. \& Schuff-Werner, P. (2000). Heat shock response is associated with protection against acute interstitial pancreatitis in rats. Digestive Diseases Sciences, 45, 2252-2264. Retrieved January 29, 2013, from http://link.springer.com/article/10.1023\%2FA\%3A1026459001195?LI=true\#page-1 doi: 10.1023/A:1026459001195 